\title{
GMR
}

\section{Genetic diversity analysis in Malaysian giant prawns using expressed sequence tag microsatellite markers for stock improvement program}

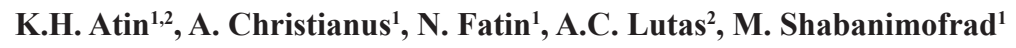 \\ and B. Subha ${ }^{2}$ \\ ${ }^{1}$ Quaculture Department, Agriculture Faculty, University Putra Malaysia, \\ Serdang, Malaysia \\ ${ }^{2}$ Genetics and Molecular Biology Div., \\ and Center of Biotechnology for Agriculture, Institute of Biological Sciences, \\ University of Malaya, Kuala Lumpur, Malaysia \\ Corresponding author: B. Subha \\ E-mail: subhabhassu@um.edu.my / subhabhassu@gmail.com
}

Genet. Mol. Res. 16 (3): gmr16035685

Received January 5, 2016

Accepted December 9, 2016

Published August 17, 2017

DOI http://dx.doi.org/10.4238/gmr16035685

Copyright $(C 2017$ The Authors. This is an open-access article distributed under the terms of the Creative Commons Attribution ShareAlike (CC BY-SA) 4.0 License.

\begin{abstract}
The Malaysian giant prawn is among the most commonly cultured species of the genus Macrobrachium. Stocks of giant prawns from four rivers in Peninsular Malaysia have been used for aquaculture over the past 25 years, which has led to repeated harvesting, restocking, and transplantation between rivers. Consequently, a stock improvement program is now important to avoid the depletion of wild stocks and the loss of genetic diversity. However, the success of such an improvement program depends on our knowledge of the genetic variation of these base populations. The aim of the current study was to estimate genetic variation and differentiation of these riverine sources using novel expressed sequence tag-microsatellite (EST-SSR) markers, which not
\end{abstract}

Genetics and Molecular Research 16 (3): gmr16035685 
only are informative on genetic diversity but also provide information on immune and metabolic traits. Our findings indicated that the tested stocks have inbreeding depression due to a significant deficiency in heterozygotes, and $F_{\text {IS }}$ was estimated as 0.15538 to 0.31938 . An $F$-statistics analysis suggested that the stocks are composed of one large panmictic population. Among the four locations, stocks from Johor, in the southern region of the peninsular, showed higher allelic and genetic diversity than the other stocks. To overcome inbreeding problems, the Johor population could be used as a base population in a stock improvement program by crossing to the other populations. The study demonstrated that EST-SSR markers can be incorporated in future marker assisted breeding to aid the proper management of the stocks by breeders and stakeholders in Malaysia.

Key words: Macrobrachium rosenbergii; Population genetics; EST microsatellites; Stock improvement program

\section{INTRODUCTION}

Freshwater aquaculture has increased rapidly in the Asia-Pacific region over the last decade. For example, the production of freshwater prawns of the genus Macrobrachium has dramatically expanded (Mather and de Bruyn, 2003). Although more than 200 species of prawns belonging to the genus Macrobrachium have been described worldwide, only a few are commercially exploited (Holthuis, 2000). The Malaysian giant prawn (MGP), Macrobrachium rosenbergii, also known as the giant freshwater prawn, is the largest and most frequently cultured Macrobrachium species with global production exceeding 200,000 tons in 2006 (FAO, 2009). Domestication of this species started in the 1960s using breeding technology developed by Dr. Shao-Wen Ling in Malaysia. Since then, stocks from the four major rivers of Peninsular Malaysia have been used for 25 years to provide the base populations for breeding programs, leading to the restocking, repeated harvesting, and transplantation of the stocks between rivers.

One of the crucial resources for stock improvement is genetic variation, which can be used to give precedence to selected populations in breeding programs (Vandeputte et al., 2004). Previous studies of genetic diversity among wild populations of Macrobrachium rosenbergii were based on allozyme markers, and they suggested low genetic variation with little evidence of population differentiation (Sodsuk and Sodsuk, 1998). In recent years, developments in molecular markers have provided a more effective tool to assess the genetic variation and to perform conventional genetic studies that were previously difficult. Simple sequence repeats (SSRs), or microsatellites, scattered throughout the genome are usually associated with a high rate of polymorphism (See et al., 2009; Kalia et al., 2011). Currently, expressed sequence tagmicrosatellite (EST-SSR) markers offer a fast, efficient, and inexpensive method compared to genomic SSRs (Gupta and Rustgi, 2004; Kalia et al., 2011). In contrast to other types of DNA marker, EST-SSR markers can be used to analyze functional diversity in both gene-rich and conserved regions of the genome (Zhang et al., 2005; Guo et al., 2006; Bhassu and Abd Rashid, 2008; Mohd-Shamsudin et al., 2011). EST-SSRs are generally less polymorphic but have greater cross-species amplification and decreased rate of null alleles in comparison with non-coding and non-transcribed regions (Kim et al., 2008).

Genetics and Molecular Research 16 (3): gmr16035685 
Wild stocks are a major resource for genetic variation and they have an important role in the future genetic improvement of aquaculture stocks. Repeated harvesting of wild stocks to restock aquacultures will eventually lead to population declines and loss of genetic diversity. In Malaysia, the practice of using riverine stocks as broodstocks decreased in 2009, as there were signs of disease in the stocks. This had led to a combined management program involving the Department of Fisheries and universities for stock improvement in three locations in Peninsular Malaysia to ensure stock integrity. The presence of genetic diversity could give choices in breeding programs regarding the maintenance of high levels of genetic variation in culture and the identification of genetically diverse broodstocks (See et al, 2008). The goal of the current study was to characterize the genetic diversity of wild MGP stocks by using seven EST-SSRs markers. The data obtained here will provide a baseline genetic assessment that will be useful in stock improvement programs.

\section{MATERIAL AND METHODS}

\section{Sample collection}

One hundred twenty wild adult Macrobrachium rosenbergii were collected from four different geographical locations in Peninsular Malaysia between March 2012 and April 2013 (Figure 1). The populations involved in this study included Tapah river in Perak, Bernam river in Selangore, Timun river in Negri Sembilan, and Johor river in Johor with a sample size of 30 individuals per population (Table 1).

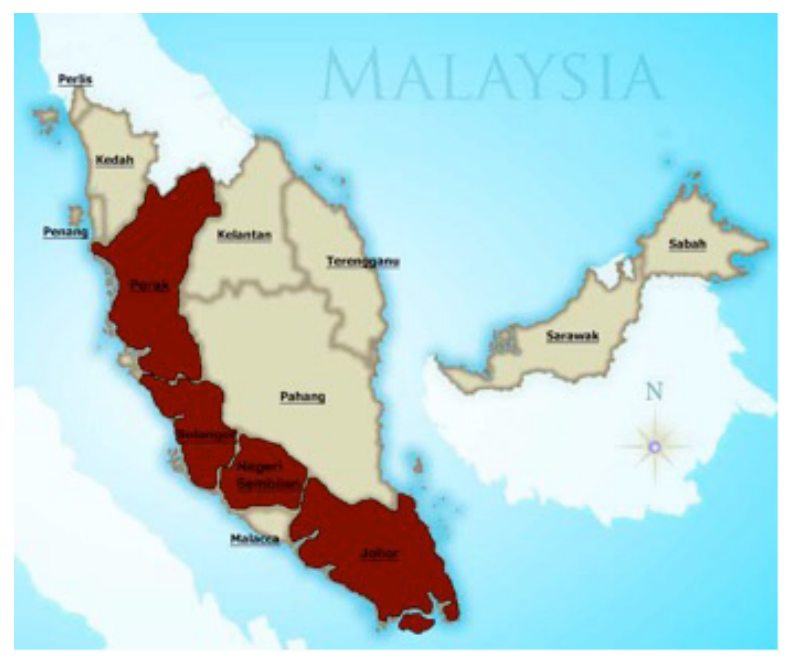

Figure 1. Sampling sites.

Table 1. Sampling sites of the studied prawn populations.

\begin{tabular}{l|l|c|c}
\hline Sampling site & State of origin & Longitude/Latitude & Sample size \\
\hline Tapah river & Perak, Malaysia & $4^{\circ} 00^{\prime} 12.0^{\prime \prime} \mathrm{N} / 100^{\circ} 51^{\prime} 39.3^{\prime \prime} \mathrm{E}$ & 30 \\
\hline Bernam river & Selangore, Malaysia & $3^{\circ} 51^{\prime} 10.3^{\prime \prime} \mathrm{N} / 100^{\circ} 56^{\prime} 31.1^{\prime \prime} \mathrm{E}$ & 30 \\
\hline Timun river & Negeri Sembilan, Malaysia & $2^{\circ} 26^{\prime} 53.3^{\prime \prime} \mathrm{N} / 102^{\circ} 03^{\prime} 42.2^{\prime \prime} \mathrm{E}$ & 30 \\
\hline Johor river & Johor, Malaysia & $1^{\circ} 43^{\prime} 38.2^{\prime \prime} \mathrm{N} / 103^{\circ} 54^{\prime} 37.5^{\prime \prime} \mathrm{E}$ & 30 \\
\hline
\end{tabular}

Genetics and Molecular Research 16 (3): gmr16035685 
Two or three pleopods (swimming legs) were removed from each prawn. Samples were preserved in $95 \%$ ethanol and were stored frozen $\left(-20^{\circ} \mathrm{C}\right)$ until further analysis.

\section{DNA extraction}

DNA was extracted from pleopods using the Promega Wizard ${ }^{\circledR}$ Genomic DNA Purification Kit and tissue extraction protocol (Promega Corporation, Madison, WI, USA). The only deviation from the protocol was incubation at $65^{\circ} \mathrm{C}$ for $90 \mathrm{~min}$ rather than $60 \mathrm{~min}$. Pleopods were cut into small pieces to aid enzymatic digestion. The concentration and the purity of each DNA sample was determined using a Nanodrop 2000 spectrophotometer (Thermo Scientific, USA); the DNA solutions were diluted to a working concentration of $50 \mathrm{ng} / \mu \mathrm{L}$ for use in PCR. Genomic DNA samples were analyzed by $2 \%$ agarose gel electrophoresis and stored at $-20^{\circ} \mathrm{C}$.

\section{EST-SSR amplification}

The primer sets for amplification of seven EST microsatellite loci are listed in Table 2. The forward primers sequences were tagged with an FAM fluorophore at the $5^{\prime}$ end. Amplification was performed using a Promega PCR Amplification Kit in a $10 \mu \mathrm{L}$ reaction mixture that included $1.2 \mu \mathrm{L} \mathrm{MgCl}_{2}, 3 \mu \mathrm{L}$ buffer, $0.25 \mu \mathrm{L}$ each dNTP, $0.4 \mu \mathrm{L}$ forward labeled primer, $0.4 \mu \mathrm{L}$ reverse primer, $0.1 \mu \mathrm{L}$ Taq polymerase, $1.9 \mu \mathrm{L} \mathrm{dH}_{2} \mathrm{O}$, and $2 \mu \mathrm{L}$ DNA template. Amplification was performed using an Eppendorf Gradient Master cycler (Eppendorf, USA) with the following conditions: initial denaturation at $94^{\circ} \mathrm{C}$ for $5 \mathrm{~min}$, then 35 cycles of $40 \mathrm{~s}$ at $94^{\circ} \mathrm{C}, 40 \mathrm{~s}$ at the annealing temperature, $40 \mathrm{~s}$ at $72^{\circ} \mathrm{C}$, followed by a final extension of $7 \mathrm{~min}$ at $72^{\circ} \mathrm{C}$.

\section{Scoring of amplified products and data integrity}

The amplification products from the PCR were diluted with deionized water (1:20 ratio), and mixed with an internal size standard (GeneScan ${ }^{\mathrm{TM}} 500$ LIZ, Applied Biosystems, Foster City, CA, USA) and Hidi formamide (Applied Biosystems). The mixture was subjected to capillary electrophoresis on an ABI PRISM ${ }^{\circledR} 3130 x l$ Genetic Analyzer (Applied Biosystems). Fragment sizes were determined using the software packages GeneMapper v4.0 (Applied Biosystems) and Peak Scanner v1.0 (Applied Biosystem). The data were collated in Microsoft Excel, and then data files for specific population genetics software were generated using the program CONVERT software version 1.31 (Glaubitz, 2004). Prior to statistical analysis, each microsatellite locus in the four stocks 1 was examined for genotyping errors caused by stuttering or large allele dropout, and for occurrence of null alleles using Microchecker version 2.2.3 (Van Oosterhout et al., 2004).

\section{Statistical analyses}

The observed number of alleles $\left(N_{\mathrm{A}}\right)$, observed $\left(H_{\mathrm{O}}\right)$ and expected $\left(H_{\mathrm{E}}\right)$ heterozygosity, and Hardy-Weinberg equilibrium (HWE) tests were estimated using POPGENE version 1.32 software (Yeh et al., 1997) with significance recalculated following the false discovery rate procedure (FDR) (Benjamini, 1995). Allelic richness was calculated using FSTAT software Version 2.9.3.2 (Goudet, 1995). Pairwise genetic differentiation $F$-statistics $\left(F_{\mathrm{ST}}\right.$ and $\left.F_{\mathrm{IS}}\right)$ were determined using ARLEQUIN 3.1 (Excoffier et al., 2007). A population tree based on pair-wise $F_{\mathrm{ST}}$ distances was constructed using the unweighed pair-group method of arithmetic averages

Genetics and Molecular Research 16 (3): gmr16035685 
(UPGMA) clustering based on Nei's (1978) unbiased genetic distances. Genetic data analysis (GDA) version 1.1 (Lewis and Zaykin, 2001) was used to illustrate the magnitude of differentiation among populations and subsequently describe the relationship between populations. The number of distinct populations $(\mathrm{K})$ represented in the set of samples was estimated from genotype data, using the program STRUCTURE 2.0 (Pritchard et al., 2000). In the population assumption menu, we set the assumed $\mathrm{K}$ value from 1 to 5 , with 500,000 repetitions of the length of the burn-in period and number of Markov chain Monte Carlo (MCMC) repetitions after the burn-in.

\section{RESULTS}

\section{Data integrity}

The Microchecker software analysis revealed no evidence for stutter error or allele dropout at any locus in any population. The possible presence of null alleles was detected at EST-Mr-AS-15334, EST-Mr-AS-1067, and EST-Mr-AS-16871 in some populations.

\section{Genetic variability within populations}

Sixty-six alleles were detected over all seven EST microsatellite loci, with a range of 5 at EST-Mr-AS-16871 to 17 at EST-Mr-AS-62230. The average number of alleles per locus varied from 4.8671 (Tapah) to 7.2857 (Johor), and the average allele richness varied from 4.7921 (Tapah) to 7.1109 (Johor) (Table 2). $H_{\mathrm{O}}$ ranged from 0.3668 (Tapah) to 0.4554 (Johor) and $H_{\mathrm{E}}$ from 0.5385 (Timun) to 0.57 (Johor). The levels of $H_{\mathrm{O}}$ were lower than expected in all populations. Significant departures from Hardy-Weinberg expectations were observed at all loci except EST-Mr-AS-31957 after applying an FDR correction (Table 3).

\section{Genetic differentiation between populations}

Pairwise genetic differentiation based on allele frequencies was determined for the four wild stocks of $M$. rosenbergii (Table 4). The analysis of pairwise genetic differentiation revealed that the $F_{\mathrm{ST}}$ values ranged from 0.01621 (Sg Timun-Bernam) to 0.08608 (Johor-Bernam), which was in line with a moderate level of genetic differentiation (Hartl and Clark, 1997).

The $F_{\text {ST }}$ value between the Tapah samples and the other three stocks displayed a significant difference $(\mathrm{P}<0.05)$. This pattern was also the case for samples from Johor, indicating Johor and Tapah were genetically differentiated from the other two sample sites.

Although the differences were shown to be statistically significant, the low value of $F_{\mathrm{ST}}$ indicated that there was only a very low degree of genetic differentiation present in the studied populations. Samples from Johor were shown to have a larger genetic difference than those from Tapah. This effect was evident in both the pairwise differentiation tests and the prevalence of unique alleles in this population. Twelve unique alleles were found in Johor samples. The inbreeding coefficient $\left(F_{\text {IS }}\right)$ was positive for all sampling sites, indicating that inbreeding has occurred in all the studied populations. The UPGMA cluster dendrogram constructed by the neighbor joining method displayed the same genetic relationships (Figure 2). The genotype cluster analysis revealed that the optimum number of populations in the four sample sites was four, indicating that there were four sub-divisions in the four wild populations (Figure 3).

Genetics and Molecular Research 16 (3): gmr16035685 
K.H. Atin et al.

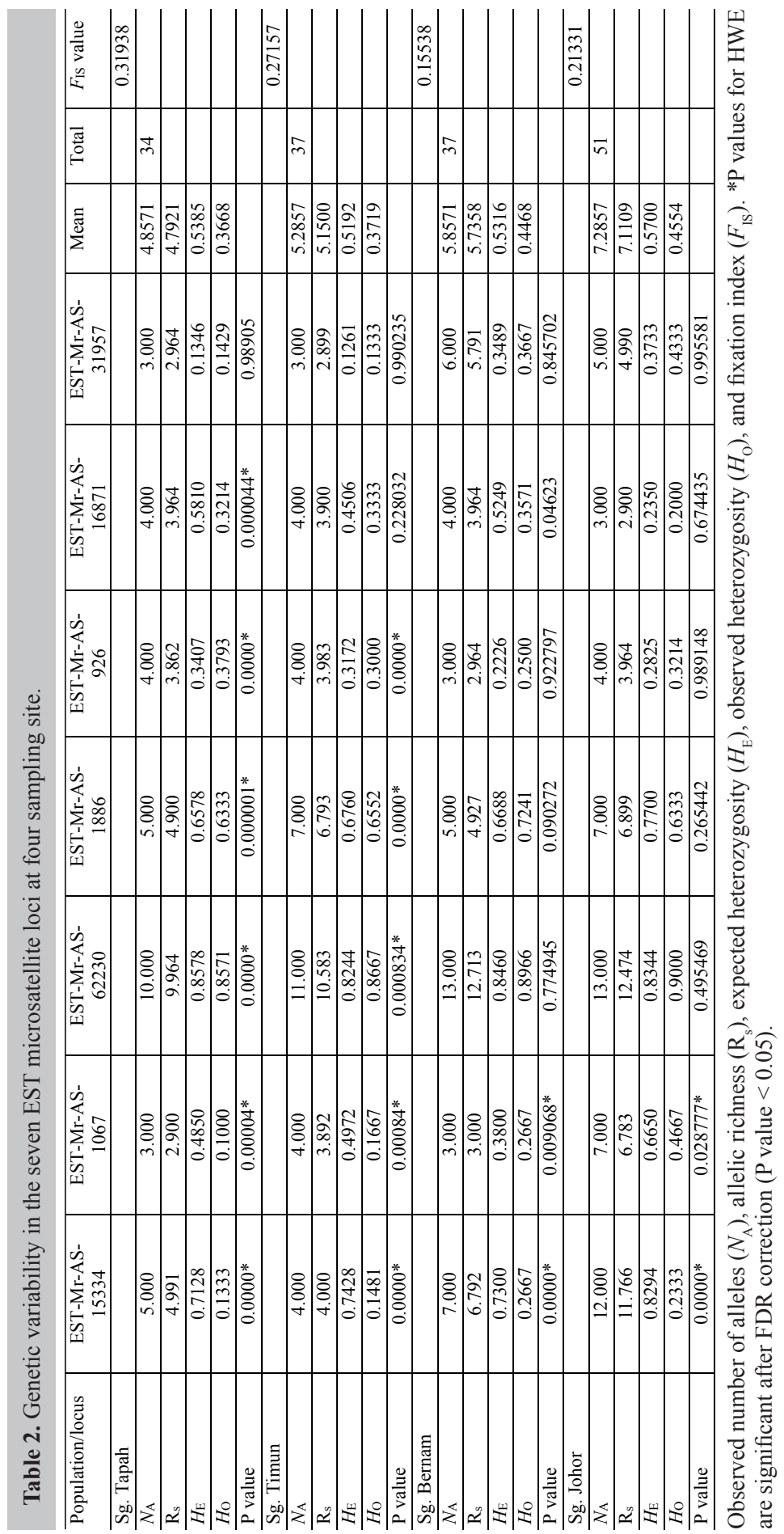

Genetics and Molecular Research 16 (3): gmr16035685 
Table 3. List of primers for the 7 EST-SSR loci in Macrobrachium rosenbergii.

\begin{tabular}{|c|c|c|c|c|}
\hline Gene ID & Primer Sequences $\left(5^{\prime}-3^{\prime}\right)$ (Forward and Reverse) & Annealing temperature $\left({ }^{\circ} \mathrm{C}\right)$ & $N_{\mathrm{A}}$ & Motif repeat \\
\hline EST-Mr-AS-15334 & $\begin{array}{l}\text { 5'-CCAAACCGATGCAATTTTCT-3' } \\
\text { 5'-CGTGGGTGCAAGTAAACACA-3' }\end{array}$ & 58.7 & 13 & $(\mathrm{GT})_{10}$ \\
\hline EST-Mr-AS-1067 & $\begin{array}{l}\text { 5'-ATTAGGTTTGCGTCGACCTC-3' } \\
\text { 5'-CCAGTCTTCTGGATGTCTTGAG-3' }\end{array}$ & 62.2 & 8 & $(\mathrm{TA})_{6}$ \\
\hline EST-Mr-AS-62230 & $\begin{array}{l}\text { 5'-CAGTCATCTCTGGGTCGTCA-3' } \\
\text { 5'-GTCCGAGTCTTCGTTGCTGT-3' }\end{array}$ & 60.8 & 17 & $(\mathrm{CAA})_{10}$ \\
\hline EST-Mr-AS-1886 & $\begin{array}{l}\text { 5'-ACGAAGCCTTTGAAGTGCC-3' } \\
\text { 5'-AGGTTTCAAATTTTCGGGCT-3' }\end{array}$ & 57.5 & 9 & $(\mathrm{CAA})_{8}$ \\
\hline EST-Mr-AS-926 & $\begin{array}{l}\text { 5'-CAACTTCATACTGATCGCCG-3' } \\
\text { 5'-GAAGACACTGAGATGAAAGACCA-3' }\end{array}$ & 57.8 & 6 & $(\mathrm{CTT})_{8}$ \\
\hline EST-Mr-AS-16871 & $\begin{array}{l}\text { 5'-AGCTTGAGGCATATCGTCGT-3' } \\
\text { 5'-GAACCACAACCGAGGACAGT-3' }\end{array}$ & 61 & 5 & $(\mathrm{TCG})_{6}$ \\
\hline EST-Mr-AS-31957 & $\begin{array}{l}\text { 5'-CCGAGAATGCTGTGGAAACT-3' } \\
\text { 5'-CAGTGCAGTCCCACAAAAGA-3' }\end{array}$ & 58.3 & 8 & $(\mathrm{CTG})_{6}$ \\
\hline Mean & & & 9.43 & \\
\hline Total & & & 66 & \\
\hline
\end{tabular}

Table 4. Matrix of pairwise comparisons of $F_{\mathrm{ST}}$ values between four populations of Macrobrachium rosenbergii.

\begin{tabular}{l|c|c|c|c}
\hline Population & Sg. Tapah & Sg. Timun & Sg. Bernam & Sg. Johor \\
\hline Sg. Tapah & & & & \\
\hline Sg. Timun & $0.02384^{*}$ & & & \\
\hline Sg. Bernam & $0.03422^{*}$ & 0.01621 & & \\
\hline Sg. Johor & $0.07694^{*}$ & $0.04573^{*}$ & $0.08608^{*}$ & \\
\hline
\end{tabular}

*P values are significant after FDR correction (P value $<0.05)$.

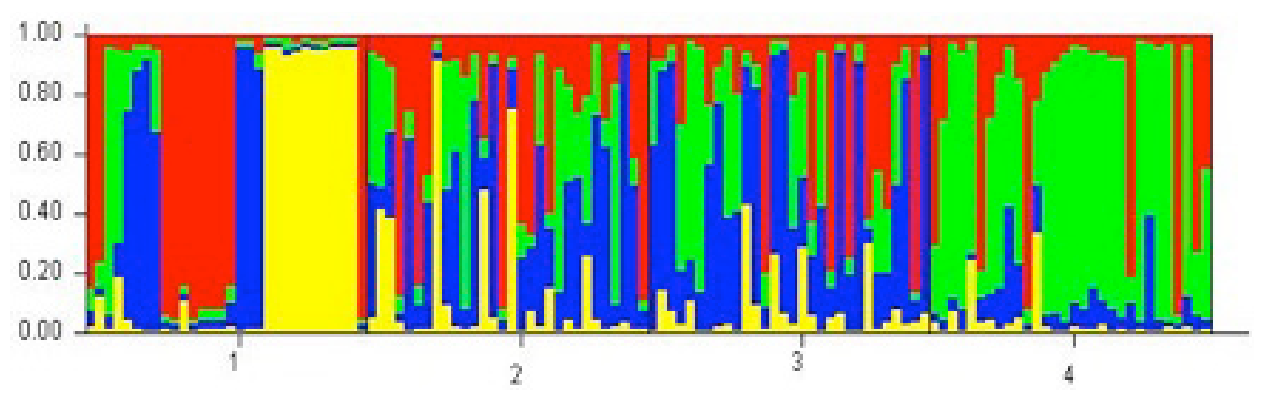

Figure 2. UPGMA dendrogram.
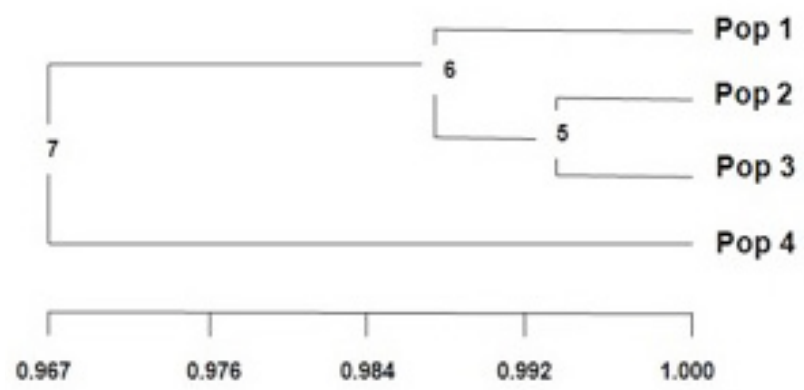

Figure 3. Bar plot of population structures.

Genetics and Molecular Research 16 (3): gmr16035685 


\section{DISCUSSION}

Genetic variation is a crucial element of a stock improvement program. Generally, high genetic variation offers greater scope for genetic improvement of traits through selection, provided that the traits are determined mainly by additive genetic factors. High genetic variation is also essential for the survival of populations as it may allow adaptation to a changing environment. However, estimating genetic variation within populations is difficult without polymorphic genetic markers (Liu and Cordes, 2004). The objective of this study was to establish the baseline data on genetic diversity of MGP populations in Malaysian rivers as part of a stock improvement program, and also to determine the potential risk of genetic diversity loss. The seven EST-SSR markers examined in this study yielded 3 to 17 alleles per locus. Previous studies on genomic SSR loci in M. rosenbergii detected 12 to 18 alleles per locus (Chand et al., 2005) and 5 to 17 alleles (Charoentawee et al., 2006). Slightly lower allelic numbers are expected using EST derived microsatellites, as the evolution of EST loci is potentially constrained by the fact that their accurate transcription may be directly or indirectly linked to important functional processes. A maximum of 51 observed alleles were found in the Johor samples, indicating that Johor contained more genetic diversity than the other locations. This finding also suggests that the Johor stock could be used in a cross-breeding program to decrease inbreeding depression in MGP populations.

The $F_{\mathrm{ST}}$ values revealed that Tapah and Johor samples were genetically different from other stocks with a low value of differentiation $(\mathrm{P}<0.05)$. This could have arisen from a genetic drift effect that might have resulted in the two populations having distinct alleles. Six of the seven EST microsatellite loci of M. rosenbergii deviated from HWE; the exception was the EST-Mr-AS-31957 locus. Although we have evidence of inbreeding in the four sampling sites, our analyses showed that all the wild populations exhibited high levels of polymorphism. Therefore, it is unlikely that inbreeding depression would have been the reason for their departure from HWE. The deviation from HWE might have been due to selection or nonrandom mating of the prawns due to specific traits, as the markers are ESTSSRs. There were no significant departures from HWE for the EST-Mr-AS-31957 locus in all four stocks; this indicates the locus was not under selection and it was stable in genotype frequency and gene frequency compared to other loci. The analysis of the four stocks in this study with genetic structure software showed that they could be divided into four potential populations (Figure 3). As the allelic frequencies were so similar among populations, then there must be ongoing gene flow between the populations. This may possibly be because of transplantation between rivers and restocking, and it affirms that the four stocks may belong to a single panmictic population.

\section{CONCLUSION}

Based on our analyses, it appears that the four studied populations are not genetically structured and that they have a high level of polymorphism. This indicates that all four populations (Tapah, Timun, Bernam, and Johor) can be considered one large (possibly) panmictic population for management purposes at present. However, the Johor stock had higher polymorphism and was a candidate for use in a cross breeding program to reduce inbreeding depression. A proper management program is needed to preserve genetic diversity for future development of MGP aquaculture.

Genetics and Molecular Research 16 (3): gmr16035685 


\section{Conflicts of interest}

The authors declare no conflict of interest.

\section{ACKNOWLEDGMENTS}

The authors would like to thank Aquaculture and \#H-30001-H000006 for the support of the grant for conducting the research, and the management of broodstock development program, which is conducted in Pusat Sains Marin, a research collaboration between UM and UPM under the \#ABI 53-02-1030.

\section{REFERENCES}

Benjamini YH (1995). Controlling false discovery rate: a practical and powerful approach to multiple testing. J.R. Stat. Soc. 57: 289-300.

Bhassu S and Abd Rashid Z (2009). Molecular and morphological approaches in discrimination of endangered Probarbus jullieni of Malaysia and Thailand stocks. Genetika 45: 1244-1249.

Chand V, De Bruyn M and Mather PB (2005). Microsatellite loci in the eastern form of the giant freshwater prawn (Macrobrachium rosenbergii). Mol. Ecol. Notes 5: 308-310. http://dx.doi.org/10.1111/j.1471-8286.2005.00910.x

Charoentawee K, Poompuang S and Na-Nakorn U (2006). Isolation and characterization of microsatellites in giant freshwater prawn Macrobrachium rosenbergii. Mol. Ecol. Notes 6: 823-825. http://dx.doi.org/10.1111/j.1471$\underline{8286.2006 .01358 . \mathrm{x}}$

Excoffier L, Laval G and Schneider S (2007). Arlequin (version 3.0): an integrated software package for population genetics data analysis. Evol. Bioinform. Online 1: 47-50.

FAO (2009). The state of world fisheries and aquaculture 2008. Food and Agriculture Organization of the United Nations, Rome.

Glaubitz JC (2004). Convert: A user-friendly program to reformat diploid genotypic data for commonly used population genetic software packages. Mol. Ecol. Notes 4: 309-310. http://dx.doi.org/10.1111/j.1471-8286.2004.00597.x

Goudet J (1995). FSTAT software Ver. 2.9.3.2. Available at [http://www2.unil.ch/popgen/softwares/fstat.htm]. Accessed February 2, 2011.

Guo W, Wang W, Zhou B and Zhang T (2006). Cross-species transferability of G. arboreum-derived EST-SSRs in the diploid species of Gossypium. Theor. Appl. Genet. 112: 1573-1581.http://dx.doi.org/10.1007/s00122-006-0261-y

Gupta PK and Rustgi S (2004). Molecular markers from the transcribed/expressed region of the genome in higher plants. Funct. Integr. Genomics 4: 139-162. http://dx.doi.org/10.1007/s10142-004-0107-0

Hartl DL and Clark AG (1997) Principles of Population Genetics. 3rd edn. Sinauer Associates, Inc, Sunderland.

Holthuis LB (2000). Nomenclature and taxonomy. In: Freshwater prawn culture: the farming of Microbrachium rosenbergii (New MB and Valenti WC, eds.). Blackwell Science Ltd., Oxford.

Kalia RK, Rai MK, Kalia S, Singh R, et al. (2011). Microsatellites markers: an overview of the recent progress in plants. Euphytica 177: 309-334. http://dx.doi.org/10.1007/s10681-010-0286-9

Kim KSR, Ratcliffe ST, French BW, Liu L, et al. (2008). Utility of EST-derived SSRs as population genetics markers in a beetle. J. Hered. 99: 112-124. http://dx.doi.org/10.1093/jhered/esm104

Lewis PO and Zaykin D (2001). Genetic data analysis: computer program for the analysis of allelic data, version 1.0 (d12). Distributed by the authors.

Liu ZJ and Cordes JF (2004). DNA marker technologies and their applications in aquaculture genetics. Aquaculture 238: 1-37. http://dx.doi.org/10.1016/j.aquaculture.2004.05.027

Mather PB and de Bruyn M (2003). Genetic diversity in wild stocks of the giant freshwater prawn (Macrobrachium rosenbergii): implications for aquaculture and conservation. Naga, World fish Center Quarterly 26: 4-7.

Mohd-Shamsudin MI, Fard MZ, Mather PB, Suleiman Z, et al. (2011). Molecular characterization of relatedness among colour variants of Asian Arowana (Scleropages formosus). Gene 490: 47-53. http://dx.doi.org/10.1016/j. gene.2011.08.025

Nei M (1978). Estimation of average heterozygosity and genetic distance from a small number of individuals. Genetics 89: 583-590.

Genetics and Molecular Research 16 (3): gmr16035685 
Pritchard JK, Stephens M and Donnelly P (2000). Inference of population structure using multilocus genotype data. Genetics 155: 945-959.

See LM, Hassan R, Tan SG and Bhassu S (2008). Genetic characterization of wild-stocks of prawns M. rosenbergii using random amplified polymorphic DNA markers. Biotechnology 7: 338-342. http://dx.doi.org/10.3923/ biotech.2008.338.342

See LM, Tan SG, Hassan R, Siraj SS, et al. (2009). Development of microsatellite markers from an enriched genomic library for the genetic analysis of the Malaysian giant freshwater prawn, Macrobrachium rosenbergii. Biochem. Genet. 47: 722-726. http://dx.doi.org/10.1007/s10528-009-9270-2

Sodsuk S and Sodsuk PK (1998). Genetic diversity of giant freshwater prawn from three locations in Thailand. Technical Paper No. 18/1998. National Aquaculture Genetics Research Institute, Pathumthani, Thailand. 40. Available at [http://agris.fao.org/agris-search/search.do?recordID=TH2000003052]. Accessed July 29, 2015.

Van Oosterhout C, Hutchinson WF, Wills DPM and Shipley P (2004). Micro-checker: software for identifying and correcting genotyping errors in microsatellite data. Mol. Ecol. Notes 4: 535-538. http://dx.doi.org/10.1111/j.14718286.2004.00684.x

Vandeputte M, Kokour M, Mauger S, Dupont-Nivet M, et al. (2004). Heritability estimates for growth-related traits using microsatellite parentage assignment in juvenile common carp (Cyprinus carpio L.). Aquaculture 235: 223-236. http:// dx.doi.org/10.1016/j.aquaculture.2003.12.019

Yeh FC, Yang RC, Boyle TBJ, Ye ZH, et al. (1997). POPGENE, the user-friendly shareware for population genetics analysis. Molecular Biology and Biotechnology Centre, University of Alberta, Edmonton.

Zhang J, Nielsen R and Yang Z (2005). Evaluation of an improved branch-site likelihood method for detecting positive selection at the molecular level. Mol. Biol. Evol. 22: 2472-2479. http://dx.doi.org/10.1093/molbev/msi237

Genetics and Molecular Research 16 (3): gmr16035685 